\title{
RECONSTRUCCIÓN GEOLÓGICA DEL VOLCÁN CHULLCANI (MIOCENO SUPERIOR A PLIOCENO SUPERIOR): CONSIDERACIONES GENERALES SOBRE GEOQUÍMICA Y EDAD DE LAS FASES VOLCÁNICAS, ANDES CENTRALES DE BOLIVIA
}

\author{
GABRIELA VARGAS-MATTOS ${ }^{1}$, MAURO CESAR GERALDES ${ }^{2} \&$ \\ RAMIRO MATOS SALINAS ${ }^{3}$
}

\begin{abstract}
Resumo El Volcán Chullcani se encuentra en el extremo Norte de la Cordillera Boliviana, entre los departamentos de Oruro y La Paz, a una altura máxima de 4600 metros sobre el nivel del mar. De acuerdo a la clasificación de nomenclatura y confirmados por el diagrama de $\mathrm{SiO}_{2} v s$. álcalis las rocas de este volcán se encuentran dentro del campo de las rocas ácidas e intermedias. Las muestras que caen en el campo de las traquidacitas, corresponden a los domos Jitiri y León Iquiña, las coladas de lava que caen en el campo de las traquiandesitas son del estratovolcán Chullcani, unidad Wuichukollu y unidad Carbon Kollu, el resto de las muestras caen en el campo de las riolitas que corresponden a las tobas y al domo Yapukkollu. Los diagramas de discriminación de las series magmáticas nos permite determinar que las rocas involucradas en el área de estudio tienen carácter subalcalino y pertenecen a la serie calcoalcalina rica en potasio. La evolución del Volcán Chullcani se desarrolló en dos periodos de tiempo, a inicios del Mioceno Medio y prosiguió en Plioceno Superior. El primer periodo se caracterizó con la extrusión de los domos Changa Mokko y Yapukkollu, para luego ser sobrepuestos por las tobas Khalani. A partir de los $6.13 \pm 0.12 \mathrm{Ma}$ se depositaron las lavas andesíticas descritas como Estratovolán Chullcani finalizando con la formación de los domos Jitiri y León Iquiña a los $6.2 \pm 0.4$ Ma. El segundo periodo de actividad volcánica, (Plioceno Superior) se distinguió por la depositación de mantos ignimbriticos de la Formación Pérez a nivel regional en la Cordillera Occidental, interrumpiendo parcialmente la evolución del Volcán Chullcani, pero es a partir de los $2.3 \pm 0.2$ Ma que se reanudó la actividad con la extrusión de las lavas Wuichukollu para alternar con las tobas Ventilla, juntamente con las brechas volcánicas. Finalizó esta intensa actividad con la formación de la meseta Carbon Kollu y el domo Pucara que actuó como un tapón sellando la actividad en la zona.
\end{abstract}

Palabras clave: Chullcani, Zona Volcánica Central, Volcanismo Neógeno del Altiplano boliviano

Abstract GEOLOGIC RECONSTRUCTION OF THE VOLCANO CHULLCANI (UPPER MIOCENE TO UPPER PLIOCENE): GENERAL CONSIDERATIONS ON GEOCHEMISTRY AND AGE OF THE VOLCANIC PHASES, CENTRAL ANDES OF BOLIVIA. The Chullcani volcano is located at Northern of Bolivian Cordillera, between Oruro and La Paz, at about 4, $600 \mathrm{~m}$ about ocean level. According to the $\mathrm{SiO}_{2}$ vs, alkalis diagrams, the studied rocks may be defined as acid to intermediate, and the $\mathrm{K}_{2} \mathrm{O}$ vs. $\mathrm{SiO}_{2}$ discrimination diagram indicates that Chullcani rocks belong to the $\mathrm{K}$-rich calcoalkaline magmatic series. The samples that fall in the field of the trachydacite, correspond to the domes Jitiri and León Iquiña, the lavas fall in the field of the trachyandesites and the estratovolcano Chullcani, unit Wuichukollu and unit Carbon Kollu, the rest of the samples fall in the field of the rhyolites that correspond to the tuffs and the dome Yapukkollu. The diagrams of discrimination of the magmatic series allow us to determine that the rocks involved in the study area have character subalcaline and they belong to the series calcoalkaline rich in potassium. The geology evolution of this volcano developed in two period of time. In the Late Miocene: the magmatic activity started with the extrusion of the Yapukkollu dome and Khalani tuff. At about $6.13 \pm 0.120$ Ma was deposited the lavas and tuffs, and followed by the formation the Jitiri and León Iquiña Domes at 6.2 \pm 0.4 Ma. Early Pliocene: In this period of time the magmatic activity in the Bolivian Cordillera was characterized by the deposition of the ignimbrite beds (Pérez Formation) at about $2.3 \pm 0.2$ Ma followed by igneous activity comprised of the Wuichukkollu lavas and Ventilla tuffs, volcanic breccias (diatremas), and finished with the Carbon Kollu Meseta and Pucara domes formation trapping actual magmatic activities.

Keywords: Chullcani, Volcanic central zone, Bolivian High-plateau Neogenic volcanism.

INTRODUCCIÓN Desde Perú hasta la Argentina pasando por territorio boliviano se eleva la Cordillera de los Andes, siendo que a partir de los $17^{\circ} 00^{\prime}-22^{\circ} 00^{\prime}$ de latitud Sur hasta los $65^{\circ}$ $00^{\prime}-70^{\circ} 00^{\prime}$ de longitud Oeste comienza la Faja volcánica occidental boliviana (Figura 1), caracterizada por ser una sucesión discontinua de picos volcánicos de 100 a $130 \mathrm{Km}$ de ancho, con anticlinales formando serranías y sinclinales concordando con valles y zonas topográficamente mas bajas. La región posee una red de drenaje endorreica, rodeada por extensos salares como el de Uyuni y Coipasa al Sur y grandes lagos como el Titicaca y el Poopó al Norte.

Los pocos trabajos geológicos que se realizaron en el área, son de carácter regional, es por eso que se considera importante el hacer una revisión de estos para luego entrar a una reconstrucción geológica mas detallada del volcán Chullcani. Sin embargo Avila (1971) publicó un estudio sobre el volcán Sajama y zonas aledañas, asignándole el nombre de Cerro Pichicani al volcán Chullcani. En su trabajo describió a la zona como una caldera de colapso recubierta por brechas de fricción con coladas de lava andesíticas y dacíticas formadas en el Pleistoceno. Dos décadas mas tarde Tröeng et al. (1996) publicaron un reporte sobre la Cordillera Occidental y el Altiplano, describiendo al cerro Chullcani como un estratovolcán, tomando como límite inferior una discordancia angular producto de la deformación de las unidades infrayacentes entre los 7 y $9 \mathrm{Ma}$, en tanto que el límite superior fue definido por una discordancia de erosión.

1 Alumna del Programa de Pos-graduación/Universidad del Estado de Rió de Janeiro (UERJ), Facultad de Geología/ Beca CAPES, Calle São Francisco Xavier, 524, Maracanã, Rio de Janeiro, Brasil, CEP: 20550-013, E-mail: gvargas_mattos@hotmail.com

2 Universidad del Estado de Rió de Janeiro (UERJ), Calle São Francisco Xavier, 524, Maracanã, Rió de Janeiro, Brasil, CEP: 20550-013

3 Universidad Mayor de San Andrés (UMSA), Calle 27 de Cota Cota, Campus universitario, Pabellon Geologia, La Paz Bolivia 


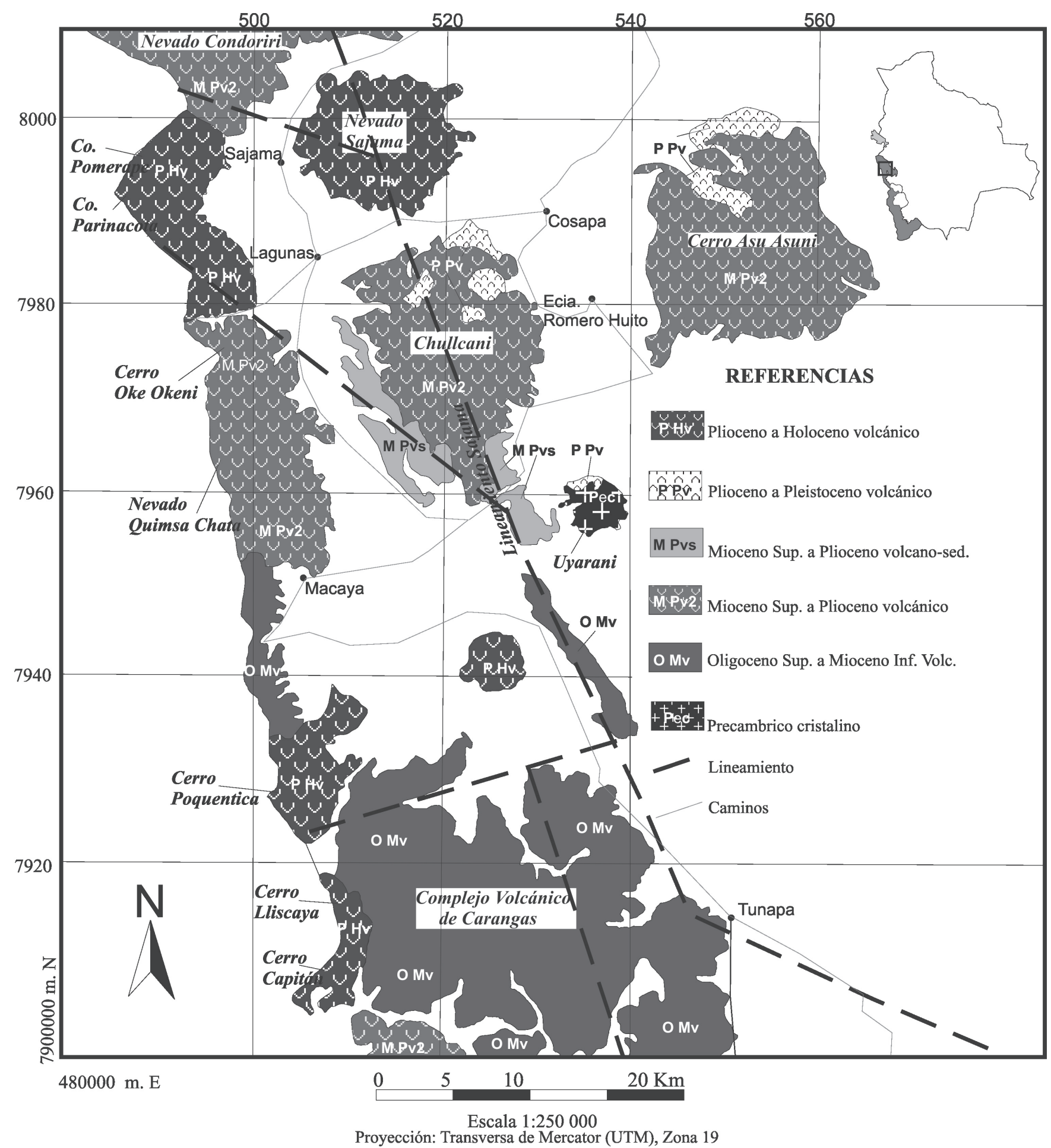

Figura 1. Mapa geológico regional

El basamento Proterozoico de la zona volcánica se encuentra representado por el Cerro Uyarani, ubicado al sudeste del Volcán Chullcani, que según Tröeng et al. (1996) se caracteriza por presentar gnaisses de color gris rosado, con bandeamentos máficos plegados y con estructuras lenticulares, estos investigadores en su trabajo presentan dataciones radiométricas en $\mathrm{Rb} / \mathrm{Sr}$ en roca total, en 15 muestras, obteniendo una edad de $1859 \pm 200$ Ma, rodeados por ignimbritas y sedimentos eólicos arenosos.

A mediados del Oligoceno-Mioceno se formaron los Complejo Volcánico de Carangas y el Volcán Chullcani. Según Avila
(1994) el Complejo Volcánico de Carangas fue descrito como dos calderas anidadas conformadas de potentes secuencias piroclásticas y lavas cuya secuencia fue producto de erupciones plinianas y volcano plinianas. Tröeng et al. (1996) también define a este mismo cuerpo volcánico como una caldera cuyo material fue el resultado de erupciones de flujos ignimbríticos juntamente con alternancia de niveles de brechas volcánicas y coladas de lava andesito-basálticas. No obstante Jiménez et al. (2000) hacen una revisión a partir de nuevos datos de campo, afirmando que el Complejo volcánico de Carangas es un domo estructural 
y no una caldera, reconocen dos unidades: la primera se trata del Complejo Pacocagua registrada como depósitos volcánicos y volcanoclásticos y la segunda unidad está representada por la faja volcánica Isluga (Chile)-Tata Sabaya (Bolivia).

El Servicio Geológico de Bolivia (SERGEOMIN) a través del Proyecto JICA-MMJA también realizó estudios en la Cordillera Occidental y Altiplano donde fue incluido el Cerro Chullcani, describiéndolo como una sucesión de tufitas riolíticas y flujos de lava andesítica.

A mediados del Mioceno a Plioceno se formaron los volcanes Asu Asuni, Condoriri, Nevado Quimsa Chata y el Cerro Oke Okeni (Figura 1). En el extremo noreste de la zona se encuentra el Complejo Volcánico Asu Asuni, descrito como un estrato volcán que forma parte de la caldera del Turaquiri (Tröng et al. 1996). La parte central está representada por una alteración hidrotermal con un núcleo de estructuras fuertemente silicificadas, cuyas rocas hospedantes están representadas por lavas de composición dacítica a andesítita y domos riolíticos.

Otro de los centros a los que se le asigna la misma edad es el Volcán Condoriri que se encuentra en la frontera con la Republica de Chile (Figura 1), al oeste del Nevado Sajama. Se define como el producto de un ambiente volcánico efusivo a explosivo. Uribe (2000) contrariamente a las edades que oscilan entre los 7 y 9 Ma postuladas por los demás autores, describe a este Complejo como un conjunto de tres estratovolcanes emplazados hace 700 000, de composición riolitica-andesitica y una colada de lava ácida desvitrificada con estructuras perlíticas y esferuliticas.

El Nevado Quimsa Chata y el Cerro Oke Okeni ubicados en la frontera con Chile y al oeste del Nevado Sajama fueron descritos por Uribe (2000) sugiriendo una edad Pleistocena. El Cerro Oke Okeni fue definido como un Complejo volcánico compuesto de dos edificios volcánicos de composición dacíticaandesítica asociado a flujos rioliticos bandeados.

Los Cerros Quisi Quisini, Poquentica, Lliscaya, Capitán, Nevado Sajama y Payachatas de edad Plioceno-Holoceno, son producto de ambientes volcánicos efusivos a explosivos asociados a la formación de estratovolcanes, según Jiménez et al. (2000) el Cerro Lliscaya es del Mioceno Superior a Plioceno.

En los nevados Payachatas (Parinacota y Pomerape) el periodo de magmatismo mas antiguo está representado por estrato volcanes de lavas andesititas y capas de ignimbritas del Pleistoceno al reciente $(<0.3 \mathrm{Ma})$. Dataciones radiométricas del estrato volcán Parinacota determinan que la última erupción es menor a los 13500 años (Wörner et al. 1988). Clavero et al (2002) proponen que el estratovolcán colapsó por la carga subyacente de sedimentos lacustres y fluvioglaciales. El edificio Parinacota se desintegró durante el colapso por el fracturamiento existente, estos volúmenes de roca fueron transportados con poca deformación interna y luego fragmentados en hummockys conforme eran depositados.

Nuevas dataciones geocronologicas en $\mathrm{C}^{14}$, según Clavero et al (2002), indican que la avalancha de detritos del Parinacota ocurrió a menos de 8.000 años ${ }_{\mathrm{BP}}$ datos obtenidos en sedimentos orgánicos ínter estratificados en tefras del lago Cotacotani.

El volcán Chullcani se encuentra en el extremo Norte de la Cordillera Boliviana (Figura 2), entre los departamentos de Oruro y La Paz, tiene una altura máxima de 4600 metros sobre el nivel del mar, cubriendo un área de $589 \mathrm{~km}^{2}$, encontrándose a los $18^{\circ} 10^{\prime}$ a $18^{\circ} 30^{\prime}$ de latitud Sur y $68^{\circ} 45^{\prime}$ a $69^{\circ} 00^{\prime}$ de longitud Oeste. El principal interés de este trabajo es la reconstrucción geológica del volcán Chullcani mediante estudios petrográficos, dataciones radiométricas y análisis de óxidos mayoritarios.

Para tal efecto los análisis que se utilizaron en este trabajo fueron 44 secciones delgadas, 27 muestras para análisis químico para óxidos mayoritarios y 3 dataciones radiométricas por el método K-Ar en biotitas y roca total. En el proceso de interpretación se utilizó el análisis modal de las secciones delgadas para identificar y clasificar las rocas de la zona de estudio, posteriormente se trabajó con el programa aplicativo IGPETWIN para confirmar el tipo de roca, por ultimo las dataciones radiométricas sirvieron para ubicar cronológicamente las unidades dentro de la escala geológica.

GEOLOGÍA DEL VOLCÁN CHULLCANI Con el fin de hacer una descripción local y reconstrucción de la actividad volcánica del Chullcani, mediante datos de campo descripciones petrográficas y dataciones radiométricas, se describirá las unidades siguiendo un orden cronológico reconociendo coladas de lava, tobas y brechas.

Domo Changa Mokko (Mioceno Superior) Una de las unidades más antiguas que se propone en este trabajo corresponde al domo Changa Mokko, situado en el extremo norte de la zona de estudio (Figura 3). Tiene $1 \mathrm{Km}$. de largo por 500 $\mathrm{m}$ de ancho, cuya cúspide se encuentra a una altura de 4110 m.s.n.m. En descripciones de campo se ha determinado que se trata de un criptodomo, de textura porfídica, de color castaño a castaño grisáceo, estructura masiva, débilmente fracturada, con fenocristales de plagioclasas y minerales máficos como ser hornblenda y piroxenos.

Microscópicamente se le asigno una composición intermedia variedad andesita con hornblenda, piroxeno y biotita. Siendo que los componentes principales son: plagioclasa de variedad oligoclasa (An ${ }_{26-30}$ ), hornblenda, biotita y como piroxenos se tiene a la augita y a la diopsida.

La oligoclasa presente en un $50 \%$ se observa con formas tabulares, zonación normal y fracturas gradacionales, en otras partes de la sección delgada la oligoclasa está parcialmente sericitizada y al parecer el núcleo está siendo reemplazado por arcillas, pero hacia la periferia este reemplazamiento disminuye.

El anfíbol hornblenda, como mineral máfico es el más abundante puesto que aparece en un $8 \%$, su forma es hexagonal y el color es castaño rojizo, con inclusiones de apatito. Al igual que la biotita este anfíbol se encuentra intensamente alterado a hematina. La mica de estas rocas es la biotita de color pardo que aparece como fenocristales de forma columnar, en algunas muestras el porcentaje de este máfico está por debajo del $2 \%$ y se encuentra fuertemente oxidado.

Los piroxenos se presentan en dos variedades, augita y diopsida, cuyos porcentajes oscilan entre 12 y $16 \%$ respectivamente. La augita en forma de prismas cortos, ocasiona la exposición del clivaje en dos direcciones y la diopsida de color castaño claro aparece en forma hexagonal, débilmente pleocróico y con inclusiones de apatito.

Los minerales accesorios están representados por el apatito, circón y minerales de hierro, a manera de inclusiones en los fenocristales máficos. Como minerales secundarios tenemos, arcillas, jarosita y pequeñas inclusiones de epidota que aparecen en los fenocristales y en la pasta.

La matriz presente en un $12 \%$, se caracteriza por tener una textura traquitica-traquitoide, representada por microlitos de plagioclasa dispuestos con una parcial orientación sobre una base desvitrificada.

Domo Yapukkollu (Mioceno Superior) En la parte sudeste del Volcán Chullcani, como se ve en la Figura 3, se encuentra el domo Yapukkollu de composición riolítica, en muestras de mano se describió a este domo como una roca félsica, de textura porfídica, de color gris blanquecino, compuesta de cuarzo, fel- 


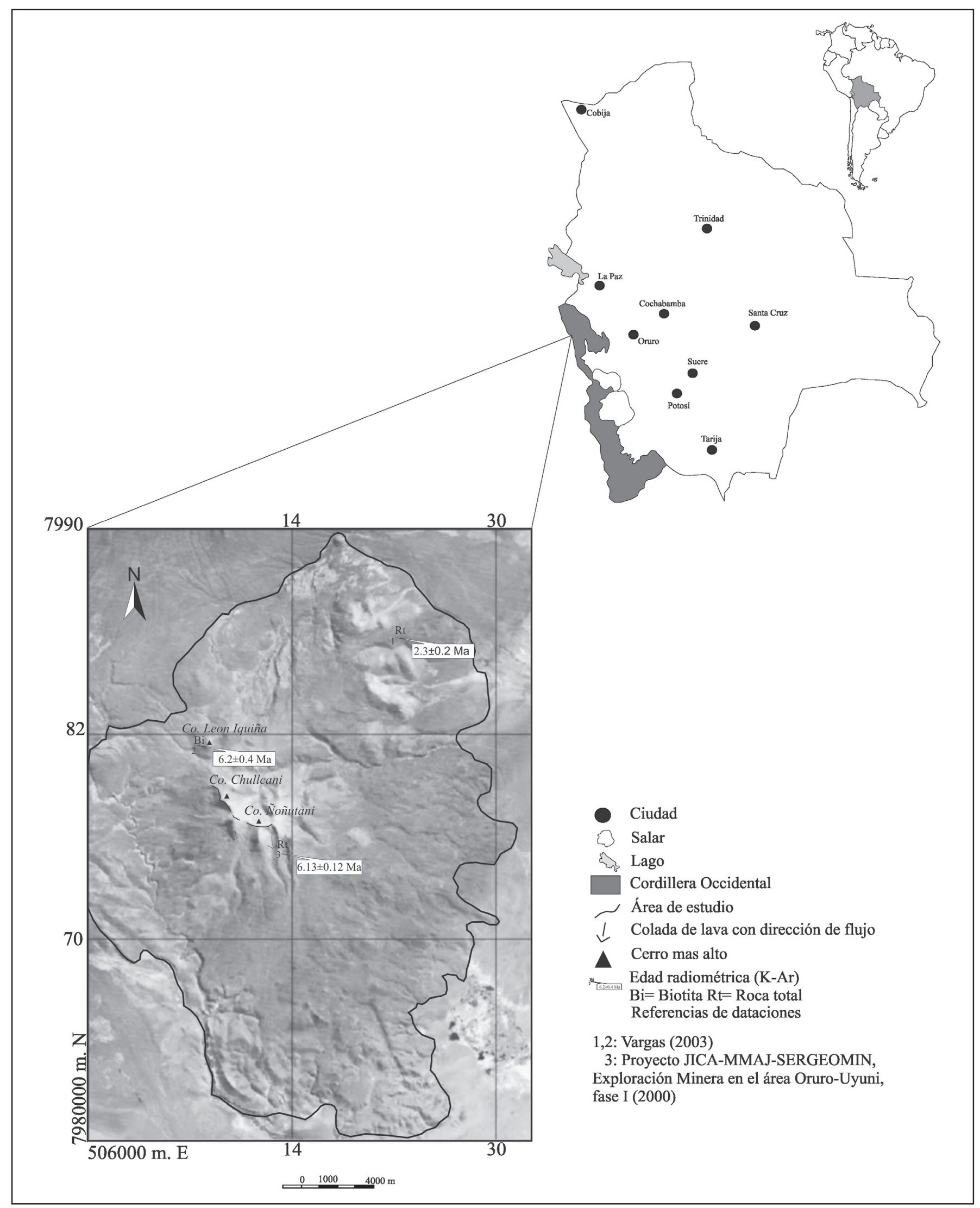

Figura 2. Mapa de ubicación de la zona de estudio.

despatos y biotita.

En análisis petrográfico este domo se caracteriza por tener: sanidina, plagioclasa, variedad oligoclasa, cuarzo y biotita que se presentan a manera de fenocristales inmersos en una pasta.
Con estos componentes se clasifico como una riolita con biotita, con alto contenido de sílice en la matriz.

La sanidina presente en un $24 \%$ representa el fenocristal felsico mas abundante de esta unidad, aparece de forma subhedral 


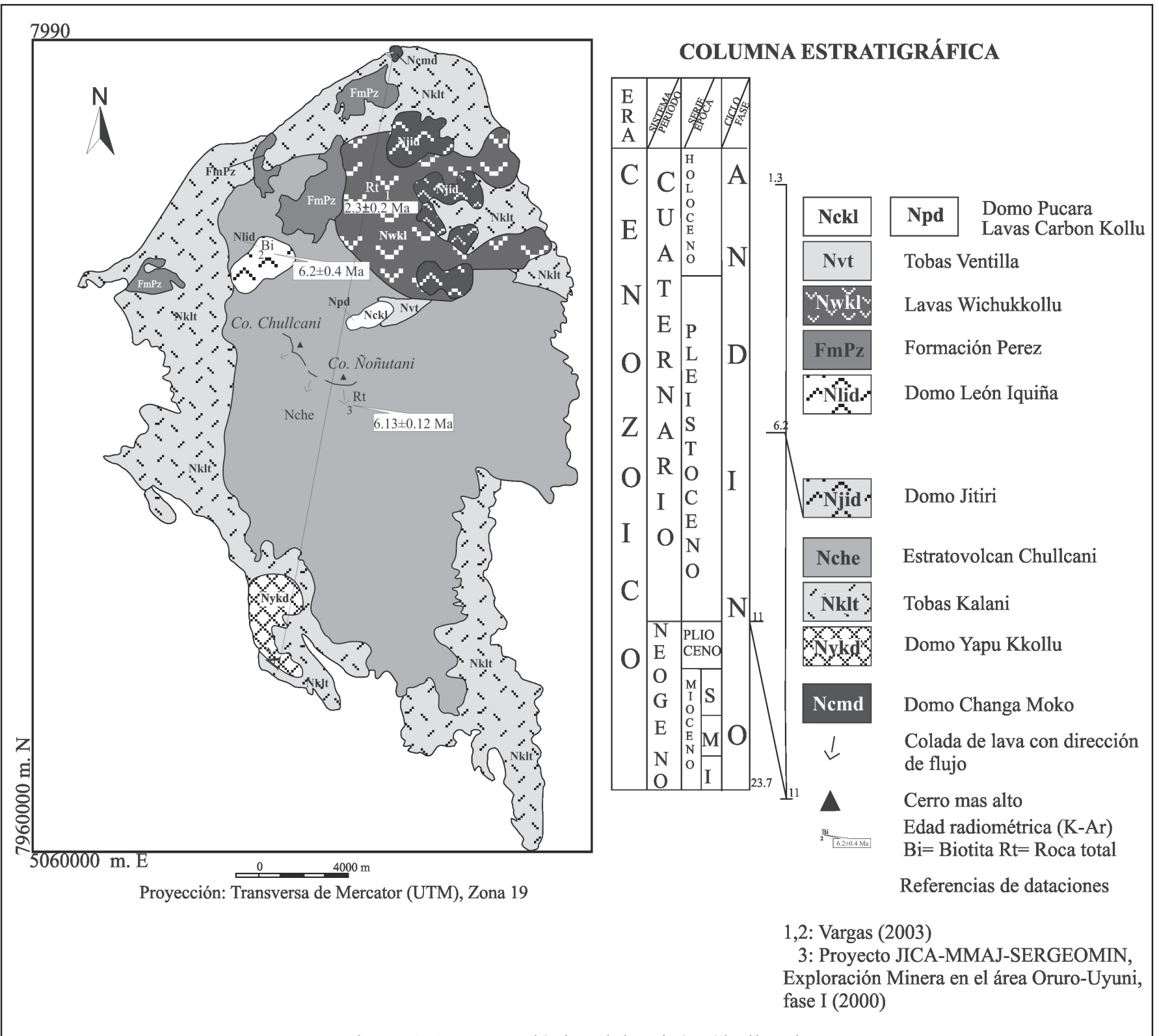

Figura 3. Mapa geológico del Volcán Chullcani

limpia, transparente y fuertemente fracturada, siendo que fácilmente puede confundirse con el cuarzo. Las plagioclasas con un $23 \%$ y de variedad oligoclasa $\left(\mathrm{An}_{24-25}\right)$, se encuentra en forma de fenocristales tabulares con maclas albita y parcialmente reemplazados por arcillas. El cuarzo con un $18 \%$, se encuentra en forma irregular y corroído por el magma de modo que la pasta se introduce en el cristal formando engolfamientos o islas.

El mineral máfico predominante en esta unidad es la biotita presente en un $2 \%$, ocurre en forma de laminillas, de color rojo a castaño producto del pleocroismo y la fuerte oxidación.

La matriz representa el $33 \%$ del total de los componentes, se caracteriza por ser vítrea, con abundante silicificación, también se presentan óxidos de hierro juntamente con agregados radiales conocidos como esferulitas.

Tobas Khalani (Mioceno Superior) Las tobas Khalani, una de las unidades con mayor extensión areal expuesta en la zona, se encuentra en la periferia del Volcán Chullcani. Los afloramientos del Rió Ventilla subyacen a las coladas de lava que proviene del Volcán Chullcani (lavas Wuichukkollu). Sin embargo en el extremo oeste se encontró un escarpe de $50 \mathrm{~m}$ de altura de material fino, deleznable con textura porfídica compuesta mayormente de clastos líticos de composición volcánica de coloración rojiza, presentes en un 30\% y con formas subredondeadas. Los pómez también se encuentran presentes, se observa longitudes de hasta $40 \mathrm{~cm}$. y por último se tiene cristales de biotita y cuarzo en un porcentaje menor comparando con los otros componentes.

Es por eso que tomando en cuenta descripciones de campo y mediante petrografía a esta toba se la ha clasificado como un depósito de flujo cristalino generado por explosiones del conducto central.

La petrografía identifica a los siguientes componentes: plagioclasa variedad oligoclasa, cuarzo, sanidina, biotita, hornblenda, apatito y óxidos de hierro. La plagioclasa es el mineral felsico que se presenta en un $8 \%$ y aparece con la variedad oligoclasa $\left(\mathrm{An}_{18-20}\right)$, estos fenocristales presentan formas tabulares, exfoliación imperfecta, macla albita y reemplazamiento parcial de arcillas, características observables tanto en la roca como en los litoclastos. 
Tabla 1. Datos obtenidos por el método radiométrico K-Ar en biotitas y roca total, GVM-2361 y HUZ-424 este estudio y 213 Tröeng et al (1996).

\begin{tabular}{|c|c|c|c|c|c|c|c|c|c|}
\hline $\begin{array}{c}\text { No de } \\
\text { muestra }\end{array}$ & Coordenadas N & Coordenadas E & Tipo de roca & Material & $\mathbf{\% K}$ & $\begin{array}{c}\text { Ar rad } \\
\text { (nl/g) }\end{array}$ & $\begin{array}{c}\text { \%Ar } \\
\text { Atm }\end{array}$ & $\begin{array}{c}\text { Edad } \\
\text { Ma }\end{array}$ & $\begin{array}{c}\text { Error } \\
(\mathbf{2} \text { \%) }\end{array}$ \\
\hline GVM-2361 & 7979750 & 515610 & Traquidacitas & Biotita & 7 & 1.622 & 71 & $6.2 \pm$ & 0.4 \\
\hline HUZ-424 & 7985113 & 524880 & Traquiandesita & Roca total & 2 & 0.237 & 63 & $2.3 \pm$ & 0.2 \\
\hline 213 & 7974520 & 520104 & Andesita & Roca total & 4 & 0.322 & 68 & $6.13 \pm$ & 0.12 \\
\hline
\end{tabular}

El cuarzo que se encuentra en un $12 \%$ aparece como fenocristales de formas subhedrales, con bordes subredondeados y a manera de inclusiones en los clastos líticos, algunos cristales aparecen corroídos por el magma ocasionando el reemplazamiento de vidrio volcánico. Otro de los minerales presentes en esta toba es la ortoclasa que se presenta en un $10 \%$ con hábito subhedral, fuertemente fracturado, exfoliación imperfecta y sericita como mineral de alteración.

Por último se identificó a la sanidina en un porcentaje no mayor al $6 \%$, de forma subhedral, relieve bajo y fuertemente fracturada.

Como minerales máficos se identificó a la biotita en un 3\% que aparece a manera de fenocristales de hábito columnar y en corte basal, el color predominante es el pardo rojizo, en tanto que el pleocroismo varía de pardo oscuro a pardo verdusco. Otro mineral máfico identificable en esta unidad es el anfíbol hornblenda que se presenta en un 5\% con formas prismáticas, de color pardo, exfoliación en dos direcciones con un ángulo de $60^{\circ}$, reemplazamiento de óxidos de hierro y rodeado por aureolas de oxido de hierro.

Los minerales secundarios presentes en esta mica son: clorita, mena de hierro y sericita que aparecen como pequeñas inclusiones y esta última a manera de alteraciones en los feldespatos potásicos.

Los clastos de origen volcánico presentes en un $14 \%$ se caracterizan por tener bordes esferulíticos con inclusiones de biotita y plagioclasas, reemplazamiento de vidrio volcánico y óxidos de hierro.

La matrix que representa el $42 \%$ del total de los componentes de la roca, se caracteriza por tener una textura con vidrio volcánico y en algunos sectores la pasta es muy esferúlitica. Como accesorios se tiene al apatito que actúa a manera de inclusiones en los minerales máficos y óxidos de hierro como mineral reemplazante. Las arcillas presentes $(<1 \%)$ aparecen específicamente en la pasta.

Estratovolcán Chullcani (Mioceno Superior) Los afloramientos correspondientes a esta unidad se encuentran en la parte central y extremo sur de la zona de estudio (Figura 3), tal es el caso de los cerros Chiarjake, Chullcani y Ñuñutani. Se ha considerado como una de las primeras efusiones del volcán Chullcani, confirmado por las dataciones radiométricas en roca total, asignando una edad de $6.13 \pm 0.12 \mathrm{Ma}$ (Tabla 1$)$. A estas rocas se las ha definido como andesitas de biotita y hornblenda, pues se presentan de color pardo, textura porfídica, dispuestas en camadas de $3 \mathrm{~m}$ de ancho, reconociendo cinco niveles del estratovolcán.

La interpretación petrográfica dio los siguientes componentes; plagioclasa de dos variedades oligoclasa-andesina, biotita, hornblenda, augita y diopsida. Los fenocristales de plagioclasa se presentan en dos variedades oligoclasa $\left(\mathrm{An}_{26-30}\right)$ y andesina
$\left(\mathrm{An}_{14-16}\right)$, representando al $74 \%$ del total de los componentes, aparecen con hábito tabular, zonación normal, fracturas gradacionales y con mineral de alteración tales como la sericita reemplazando el núcleo de algunas plagioclasas.

Los maficos son biotita y hornblenda representando el 14\% del total de los minerales, el primero presenta una coloración parda que aparece con formas tabulares y hexagonales por el corte basal, en algunas muestras el porcentaje de este máfico está por debajo del 5\% y con una fuerte oxidación. En algunas muestras la mica esta completamente reabsorbida quedando únicamente granos y polvo de magnetita conservando el clivaje y la forma. El segundo mineral máfico aparece con hábito hexagonal, de color castaño rojizo con inclusiones de apatito, al igual que la biotita este mineral se encuentra reabsorbido por el magma.

Por otra parte en esta roca se encontró el piroxeno de variedad augita correspondiente al $12 \%$ del total de los componentes, se presenta a manera de prismas cortos ocasionando la exposición del clivaje en dos direcciones, pleocróico, exfoliación paralela, relieve alto, color castaño amarillento y ángulo de extinción de $37^{\circ}$.

Entre los minerales que se presentan con carácter de accesorios figuran el apatito y la magnetita que aparecen en algunos casos a manera de inclusiones y/o en la pasta. En cuanto a la matriz se pudo determinar que está representado por microlitos de plagioclasa dispuestos con orientación parcial en una base vítrea, con textura traquitica-traquitoide.

Domo Jitiri (Mioceno Superior) Se ha asignado el nombre de domo Jitiri a una serie de cinco cerros, alineados en la parte noreste de la zona de investigación (Figura 3), ubicados a $6 \mathrm{Km}$. de la población de Cosapa correspondientes a los cerros Jitiri, Picha Kkollu, Llallani, Jachcha Kuchu y Wila Latarata. Una de las mejores exposiciones de estos domos es el cerro Jitiri, del cual se tomo el nombre. Esta unidad se presenta como un domo lava, de composición dacítica con biotita, de coloración rosada blanquecina, con cristales de cuarzo, feldespatos y biotita inmersos en una pasta criptocristalina.

Microscópicamente se identificó los siguientes componentes: cuarzo, plagioclasa como minerales felsicos y hornblenda, biotita y esfena como representantes máficos en menor proporción. El cuarzo en un $6 \%$ se presenta como fenocristales de formas subhedrales a anhedrales y reabsorbidos por el magma por lo que se observa engolfamientos. La plagioclasa uno de los minerales más abundantes $(51 \%)$ corresponde a la variedad oligoclasa $\left(\mathrm{An}_{65-10}\right)$, apareciendo como fenocristales tabulares o también como glomeropórfidos, la mayoría de los fenocristales presentan zonación normal, algunos de los cristales se encuentran fracturados y rellenados con vidrio volcánico.

Como máficos se tiene fenocristales de hornblenda presentes en un $2 \%$, con hábito hexagonal, color pardo verdusco y con bordes oscuros rodeados por óxidos de hierro. Algunos 
fenocristales están completamente reemplazados por el oxido de hierro producto de la reabsorción magmática, reconociéndolo solo por la forma, otros cristales presenta fracturas rellenadas por sílice. Otro máfico presente es la biotita, que aparece en un $7 \%$, de hábito tabular y formas hexagonales, el color predominante es el castaño a castaño rojizo con inclusiones de apatito, la mayoría de esos cristales presentan aureolas de óxidos de hierro, incluso algunos se encuentran totalmente reemplazados por este mineral secundario.

Los minerales secundarios y accesorios son comunes y no merecen especial atención, sin embargo se hace presente la esfena en un $1 \%$, de forma rómbica, color marrón pálido y relieve alto. La matrix que representa el 33\% del total de los componentes de la roca, se presenta con abundante vidrio volcánico y minerales de alteración tales como las arcillas.

Domo León Iquiña (Mioceno Superior) El domo León Iquiña, que lleva el nombre del mismo cerro, ubicado en la parte central de la zona de estudio (Figura 3), presenta dataciones radiométricas por el método $\mathrm{K}-\mathrm{Ar}$ en biotita dando una edad de 6.2 $\pm 0.4 \mathrm{Ma}$ (Tabla 1). Por las observaciones de campo y descripciones petrográficas se ha clasificado como un domo de composición dacítica con biotita y hornblenda. La coloración es gris blanquecina en superficie fresca y marrón en superficie alterada, la textura es porfídica, los cristales predominantes son el cuarzo, biotita, hornblenda y la matrix es cristalina.

Microscópicamente se observan plagioclasas, cuarzo, hornblenda y biotita. Siendo que el mineral abundante es la plagioclasa que se presenta en un $56 \%$ con la variedad oligoclasa $\left(\mathrm{An}_{15-16}\right)$, de formas subhedrales, con zonación normal, macla albita y con algunas desvitrificaciones visibles donde se pudo identificar la alteración sericítica. El cuarzo es el siguiente mineral felsico, con un $35 \%$ en abundancia, de formas subhedrales, algunos cristales presentan engolfamientos productos de la reabsorción del magma y particularmente en este tipo de rocas es común la presencia de sílice a manera de reemplazamiento.

Como minerales máficos presentes en esta roca identificamos a la hornblenda, que aparece en un $4 \%$, se presenta de forma hexagonal, fuertemente pleocróica, de color pardo, con inclusiones de apatito y algunos cristales se encuentran cloritizados. La mica se hace presente con la variedad biotita, que representa el $5 \%$ del total de los constituyentes, aparece en forma de laminillas donde algunas de las placas se encuentran curvadas, el color varia de rojo a castaño rojizo y el pleocroismo va de castaño hasta pardo verdusco.

Como minerales accesorios se encuentra el apatito, esfena y óxidos de hierro los cuales actúan a manera de inclusiones. La matriz es de grano fino, de textura traquitoide con presencia de arcillas y por la extinción ondular que se observa en algunas zonas, se tiene abundante desvitrificación.

Formación Pérez (Plioceno Superior) Forbes (1861) describió a estas rocas como una serie escalonada de capas traquiticas tufáceas. No obstante Sirvas-Carranza (1964) describió por primera vez como Formación Pérez en la estación Pérez del ferrocarril Arica- La Paz, de donde proviene el nombre, atribuyendo su formación al derrame de éstas a través de largas fisuras para luego ser depositadas en superficie en forma de lavas (SuarezSoruco \& Diaz-Martines 1996). Ponce y Avila (1964) encuentran similitud y describen afloramientos de esta formación en la porción norte del Volcán Chullcani, asignando el nombre de ignimbritas blancas y rosadas de composición riodacítica.

Estos afloramientos se encuentran en la parte norte del Volcán Chullcani (quebradas Esquillani y Huancoaki). Los afloramientos de la quebrada Huancoaki tiene una altura de 50 a $55 \mathrm{~m}$, la coloración predominante es rosado blanquecina con fracturas con dirección Norte-Sur. Los componentes principales reconocidos en campo son: cuarzo, biotita, feldespatos y líticos volcánicos de $7 \mathrm{~cm}$ de largo y pómez de $0.5 \mathrm{~cm}$. de largo, inmersos en una pasta fina.

La interpretación petrográfica dio los siguientes componentes: plagioclasa de variedad oligoclasa, cuarzo, sanidina, biotita, piroxenos y como minerales accesorios apatito y hematina. La plagioclasa es el constituyente félsico mas abundante de la roca (alrededor del 20\%), correspondientes a la variedad oligoclasa $\left(\mathrm{An}_{12.5-13.5}\right)$ y aparecen en fenocristales tabulares que a menudo se encuentran fuertemente fracturados con los bordes subredondeados y corroídos.

El cuarzo presente en un 5\% se encuentra a manera de fenocristales subhedrales a anhedrales rodeados por esferulitas. Así mismo el feldespato potásico que predomina es la sanidina, puesto que se manifiesta en un $15 \%$ y aparece a manera de fenocristales subhedrales con fracturas rellenadas por sericita.

Como fenocristales máficos se identificó a la biotita presente en un $12 \%$, de color castaño, fuertemente oxidado, desarrollado en forma de laminillas y con inclusiones de apatito. Los piroxenos presentes en un $7 \%$ son pequeños cristales cuya variedad es difícil distinguir, pero probablemente se trata de una hiperstena debido a los colores de interferencia que van hasta amarillo de primer orden.

Como minerales accesorios se tiene al apatito $(<1 \%)$ que se encuentra como inclusiones en los fenocristales máficos, la hematina $(1 \%)$ reconocida por su color rojo intenso y el óxido de hierro $(5 \%)$ de color gris oscuro rodean formando aureolas en la mayoría de los fenocristales máficos. El matrix representa el $40 \%$ del total de los componentes de la roca, fuertemente esferulítico y con sílice amorfa.

Lavas Wichukkollu (Plioceno Superior) Son flujos de lavas que se encuentran en la parte noreste de la zona de estudio (Figura 3), cuyos afloramientos se hallan mejor expuestos en las quebradas Khoyani, León Iquiña y Loma Wichukkollu de donde se tomó el nombre. Asimismo esta roca aflora en el extremo este de la zona volcánica entrando por el Río Ventilla, donde se observa el contacto entre estas coladas vesiculares y el nivel superior de las Tobas Khalani.

Estos afloramientos se definen como coladas de lava andesiticas con augita, de textura fina, con piroxenos y biotita que han sido datadas por el método radiométrico K-Ar en roca total, obteniendo una edad de $2.3 \pm 0.2$ Ma (Tabla 1). Petrográficamente los componentes de esta unidad son: plagioclasa, biotita y augita. La plagioclasa que abunda en la sección es la variedad oligoclasa $\left(\mathrm{An}_{12-13}\right)$ puesto que se tiene como único mineral félsico $(75 \%)$, estos fenocristales se presentan en formas tabulares y aparecen maclados según la ley de la albita, es muy frecuente encontrar en estas lavas reemplazamientos sericiticos principalmente en el centro del cristal de las plagioclasas.

La mica presente en esta roca es la biotita de color castaño, en un porcentaje muy bajo (1\%), con formas tabulares. Es frecuente encontrar en esta sección otros fenocristales corroídos por el magma e inclusiones de apatito y/o óxidos de hierro, la alteración característica de esta mica es la clorita por lo que adquiere esa tonalidad verdosa.

Los piroxenos se hacen presentes en un 3\%, donde los fenocristales aparecen de formas hexagonales, de color verde pálido y frecuentemente maclados. Como minerales accesorios se tiene al apatito y la mena de hierro que se dispone a manera de inclusiones en los máficos.

La matrix con un $21 \%$ está conformada por microlitos de plagioclasas con oquedades rellenadas por clorita y sericita lo que le da una textura intersertal. 
Tobas Ventilla (Plioceno Superior) Esta toba lítica de flujo se encuentra en la parte central del Volcán Chullcani, al norte del Cerro Huayna Chullcani entrando por el Río Ventilla, se extiende cubriendo un área no mayor a los $2.5 \mathrm{~km}^{2}$ (Figura 3). Definido como flujos de ceniza líticos producto del colapso del domo Pucara, se presentan con una coloración gris blanquecina con bloques de andesitas de $35 \mathrm{~cm}$. de largo por $20 \mathrm{~cm}$. de ancho, fragmentos de pómez de color blanquecino fácilmente deleznables y cristales de biotita en menor proporción.

Petrográficamente, esta toba presenta abundantes líticos, cristales de cuarzo, plagioclasa, biotita y vidrio volcánico en la matriz. Los líticos de origen volcánico que aparecen en un $18 \%$ del total de los componentes se caracterizan por presentar formas alargadas, de color castaño oscuro producto de las inclusiones de óxidos de hierro y de hojuelas de biotita ferruginosa.

El cuarzo se presenta en un 5\% y sus cristales adquieren formas subhedrales y engolfamientos producto de la corrosión magmática. La plagioclasa presente en un $2 \%$ es de la variedad andesina $\left(\mathrm{An}_{26-27}\right)$ se encuentra presente como fenocristales tabulares y con agregados de sericita desarrollados en los núcleos. La biotita (2\%) está presente en cristales de forma columnar, color castaño, exfoliación en una dirección y tiene la particularidad de ser observable en la roca y también en los clastos líticos.

El vidrio volcánico (7\%) está restringido al matriz y reemplazando a algunos cristales de cuarzo. Como minerales accesorios predominan los óxidos de hierro que tienen la particularidad de presentarse en forma de inclusiones.

Por último la matriz (54\%) es de carácter vítreo, con presencia subordinada de feldespatos potásicos y menas de hierro.

Lavas Carbon Kollu (Plioceno Superior) Estas lavas forman una meseta de $1 \mathrm{Km}$. de largo por $500 \mathrm{~m}$ de ancho y se encuentra en la parte central de la zona de estudio (Figura 3) y se distingue por su extensión local, es decir, casi paralela al Río Ventilla, al norte del Cerro Huayna Chullcani. Esta colada de lava clasificada como andesitas basáltica con olivino, se caracteriza por tener una coloración oscura y textura porfídica.

Para una descripción más completa se hicieron secciones delgadas en las cuales se encontró los siguientes componentes: olivino como mineral predominante, vidrio volcánico y microlitos de plagioclasa restringidos a la pasta y hematina, juntamente con apatito como minerales accesorios.

Los fenocristales de olivino presentes en un $12 \%$ aparecen incoloros en nícoles paralelos, relieve alto, formas hexagonales, débilmente pleocroico y con aureolas de hematina, algunos de ellos se encuentran maclados.

El vidrio volcánico presente en un $6 \%$, del total de los componentes, se encuentra a manera de masas amorfas restringidas al matriz o rodeando a la mayoría de los olivinos.

La hematina considerada como minerales accesorios aparecen en un $4 \%$ en esta roca, de color gris oscuro, se presentan con formas anhedrales y aparecen estrictamente rodeando a los máficos en el matriz.

La matriz presente en un $28 \%$ está rellenada con vidrio volcánico y presenta microlitos alargados de plagioclasa, con maclas del tipo albita y textura traquítica. Como minerales secundarios o de alteración se tiene a los epidotos de coloración verde amarillenta inmersos en la pasta.

Domo Pucara (Plioceno Superior) Esta estructura de forma circular y de $500 \mathrm{~m}$ de diámetro se encuentra en la parte central de la zona de estudio. Se trata de un domo lava de composición andesita basáltica con olivino, de coloración gris oscura, textura porfídica y con cristales de piroxeno y biotitas, el cual corresponde a la última fase efusiva del evento lavas Carbon Kollu, por lo que para fines prácticos no se repetirá la descrip- ción petrográfica.

Brechas La brecha volcánica de relleno o diatrema se encuentra en la parte central y en la quebrada Paotani, se caracteriza por presentar fragmentos de roca grandes unidos por un matriz de grano fino y de color rojo escarlata a gris rojizo debido al contenido de óxidos a consecuencia de la presencia de limonita y goetita. Los fragmentos de roca volcánica, de formas angulosas de 5 a $7 \mathrm{~cm}$. de largo, se encuentran fuertemente silicificados.

Estas brechas se caracterizan porque aparecen vetillas silicificadas de $30 \mathrm{~cm}$. de ancho por $1 \mathrm{~m}$ de lago dispuestas en forma radial. Hacia el este (quebrada Paotani) se encuentra el segundo afloramiento, donde las rocas se encuentran fuertemente argilizadas tanto la matriz como los fragmentos líticos.

Petrográficamente los componentes encontrados son: fenocristales de plagioclasa, fragmentos líticos, maficos que están totalmente reemplazados por lo que sólo se puede reconocer por las formas y la pasta. Los clastos monolitológicos son angulosos a redondeados, aparecen de color castaño claro, fuertemente silicificados y en menor proporción algunos clastos se encuentran argilizados. La matriz es microcristalina, oxidada, de color rojo escarlata debido al contenido de hematina, también se advierte la presencia de desvitrificación

GEOQUÍMICA Se tomó un total de 29 muestras para análisis de roca total (Tabla 2), muestras que fueron analizadas mediante e Fluorescencia de rayos X que servirán para entender los procesos envueltos en la petrogénesis de las rocas involucradas en la formación del volcán Chullcani y para reconocer las series magmática. Para tal efecto utilizamos el diagrama clasificatorio de sílice vs álcalis (TAS) propuesto por Le Maitre et al. (1989) y la siguiente secuencia de diagramas para la discriminación magmática como el de Harker (1909), el diagrama ternario AFM propuesto por Irvine \& Baragar (1971) y el diagrama de $\mathrm{SiO}_{2} v s$. $\mathrm{K}_{2} \mathrm{O}$ propuesto por Pecerrillo \& Taylor (1976), para determinar el contenido de potasio.

El diagrama TAS propuesto por Le Maitre et al. (1989), como se observa en la Figura 4, muestra que las rocas del volcán Chullcani caen en el campo de las rocas intermedias, la distribución de las rocas es la siguiente: las coladas de lava caen en el campo de las traquiandesitas y se diferencian por tener el menor porcentaje de sílice $(57$ y $62.5 \%$ ) y álcalis (6 a $8 \%$ ). Las muestras que caen en el campo de las traquidacitas, corresponden a los domos, con marcado aumento de sílice (63 a 70\%) y $8 \%$ de álcalis y el resto de las muestras caen en el campo de las riolitas que corresponden a las tobas y particularmente la muestra GVM-2355 del domo Yapukkollu.

Mediante el uso de los elementos mayoritarios se hizo una discriminación magmática, como se presenta en el gráfico de la Figura 5. En este, se observa la variación composicional clasificando al Volcán Chullcani como rocas de carácter subalcalino con un elevado contenido de sílice, salvo la muestra HUZ-424 que se presenta con una tendencia alcalina.

Esta serie subalcalina a su vez a sido presentada en el diagrama ternario AFM, propuesta por Irvine \& Baragar (1971), mostrando que las rocas del volcán Chullcani corresponden a la serie de magmas calcoalcalinos, como se observa en la Figura 6, donde las lavas presentan un porcentaje menor en el contenido de álcalis y hierro.

Por último tenemos el diagrama de $\mathrm{SiO}_{2}$ vs $\mathrm{K}_{2} \mathrm{O}$ propuesto por Pecerrillo \& Taylor (1976), clasificando a las rocas de la zona de estudio, como calcoalcalinas con alto contenido de potasio, con un rango que oscila entre $3-6 \% \mathrm{~K}_{2} \mathrm{O}$, como se observa en la Figura 7. 


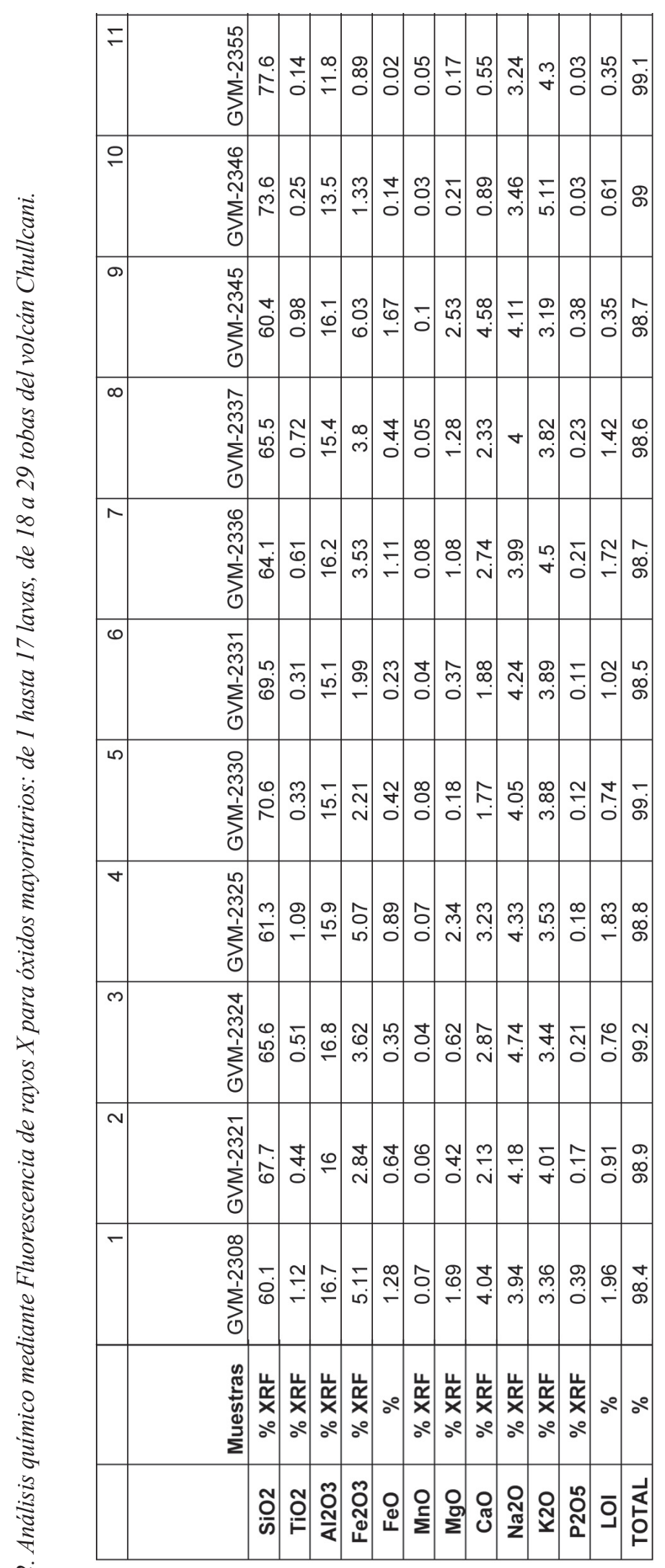

\begin{tabular}{|c|c|c|c|c|c|c|c|c|c|c|c|}
\hline$\stackrel{N}{N}$ & $\begin{array}{l}\text { N丶 } \\
\text { İ } \\
\end{array}$ & $\Sigma$ & $\stackrel{m}{\longrightarrow}$ & $\stackrel{m}{-}$ & ָ̃. & 0 & & $\mid$ & $\overline{0}$ & 5 & $\stackrel{\mathrm{N}}{\mathrm{N}}$ \\
\hline $\mathbb{\infty}_{\infty}^{\infty}$ & ปิ & $\stackrel{+}{\dot{T}}$ & $=\stackrel{\infty}{\stackrel{\infty}{\stackrel{m}{\sim}}}$ & $\begin{array}{l}5 \\
\text { o. } \\
0\end{array}$ & & t. & & \begin{tabular}{|l} 
\\
$\sim$ \\
$\sim$
\end{tabular} & $\begin{array}{l}\text { D. } \\
\vdots \\
i \\
\end{array}$ & $\begin{array}{l}0 \\
0 \\
0 \\
0\end{array}$ & 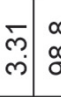 \\
\hline$\stackrel{\sim}{\sim}$ & $\stackrel{N}{\vec{I}} \overline{\mathrm{q}}$ & $\stackrel{c}{c}$ & $\stackrel{\square}{=}$ & $\stackrel{+}{-}$ & 0 & 5 & $=$ & $\hat{m}$ & $\stackrel{\infty}{+}$ & $\overline{0}$ & $\stackrel{m}{\circ}:$ \\
\hline$\stackrel{\Omega}{\Omega}$ & సેं & \pm & $\stackrel{v}{s}$ & $\stackrel{+}{\leftarrow}$ & $\check{0}$ & 0 & & $\stackrel{\odot}{\rho}$ & $\stackrel{\leftrightarrow}{+}$ & $\check{0}$ & $\stackrel{0}{\circ}$ \\
\hline กี & 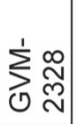 & ¿े. & 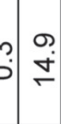 & $\stackrel{\bar{\infty}}{\leftarrow}$ & 苂. & ?. & & 吕 & 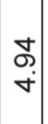 & : & \begin{tabular}{l} 
\\
\hdashline \\
0
\end{tabular} \\
\hline$\underset{\sim}{2}$ & उo & నุ. & 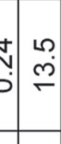 & $\stackrel{\overbrace{}}{\leftarrow}$ & 年 & f & & 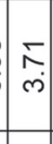 & ז̦ & ô. & \begin{tabular}{l|l}
0 \\
$\vdots$ \\
$\vdots$ \\
0 \\
0
\end{tabular} \\
\hline$\stackrel{\sim}{N}$ & $\sum_{0}^{3}$ & 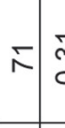 & $\vec{b}$ & $\stackrel{\widehat{o}}{\dot{\alpha}}$ & ָ̦ & 5 & & 量 & 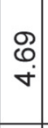 & $\overline{0}$ & 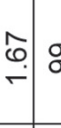 \\
\hline $\mathrm{N}$ & O) & $\begin{array}{lll}0 \\
0 \\
0\end{array}$ & 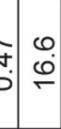 & 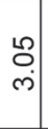 & $\stackrel{0}{:}$ & t. & & 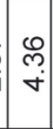 & $\hat{\omega}$ & $\stackrel{\oplus}{\circ}$ & \begin{tabular}{c|c}
$\stackrel{\infty}{\circ}$ \\
$\stackrel{8}{-}$
\end{tabular} \\
\hline $\bar{\sim}$ & 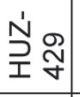 & Б্ণ) & 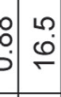 & \begin{tabular}{|c|c|}
$\infty$ \\
$\infty$ \\
\llcorner \\
\end{tabular} & 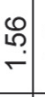 & $\bar{s}$ & ๙ & テै & $\bar{\oplus}$ & $\begin{array}{l}\hat{N} \\
0\end{array}$ & 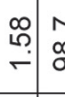 \\
\hline ని & 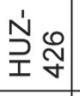 & 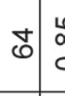 & $\begin{array}{l}0 \\
:\end{array}$ & $\overline{\grave{q}}$ & . & ? & 3 & $\stackrel{5}{\dot{t}}$ & ڤ્. & ल) & 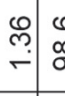 \\
\hline 잉 & 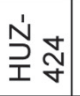 & 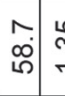 & 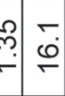 & $\stackrel{\substack{0 \\
0}}{.}$ & م. & 0 & & 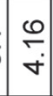 & 苞 & . & 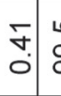 \\
\hline$\stackrel{\infty}{\stackrel{\infty}{~}}$ & 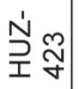 & \begin{tabular}{l|l}
$m$ & 0 \\
\hdashline & $\vdots$
\end{tabular} & $\begin{array}{c}\text { of } \\
\text { | }\end{array}$ & $\begin{array}{l}0 \\
\stackrel{\rho}{\rho}\end{array}$ & 周. & :. & $\vec{s}$ & f & 怘 & $\stackrel{0}{0}$ & $\hat{o}: 0$ \\
\hline 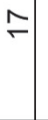 & $\sum_{0}^{3} \overline{\mathrm{N}}$ & ${ }^{\circ}$ & $\stackrel{\vec{b}}{b}$ & $\stackrel{\hat{\infty}}{\stackrel{\leftrightarrow}{\leftarrow}}$ & 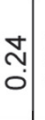 & a & & 帛 & $\begin{array}{l}\stackrel{\mathscr{O}}{+} \\
\stackrel{+}{0}\end{array}$ & $\check{\circ}$ & $\stackrel{\hat{\sigma}}{\cdot}$ \\
\hline$\stackrel{\varphi}{\stackrel{0}{2}}$ & S1 & 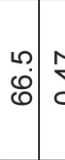 & $\begin{array}{l} \\
\\
\end{array}$ & 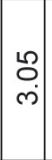 & & 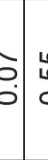 & & 曽 & $\hat{\oplus}$ & $\stackrel{9}{\circ}$ & 足 \\
\hline$\stackrel{2}{\llcorner}$ & కృ & ค่ & $\underset{0}{\infty}$ & $\stackrel{0}{0}$ & & 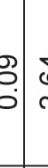 & & 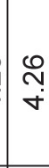 & $\bar{\sigma}_{\mathbf{S}}$ & & \begin{tabular}{l|l}
0 \\
+ \\
0
\end{tabular} \\
\hline \pm & $\sum_{0}^{5}$ & 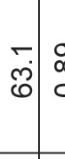 & فِ & $\underset{\sim}{\mathbb{\sim}}$ & & & & 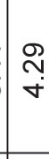 & $\stackrel{\infty}{\stackrel{\infty}{\infty}}$ & & $\stackrel{\mathscr{g}}{\circ}$ \\
\hline$\stackrel{m}{\stackrel{m}{2}}$ & 永 & $\stackrel{0}{0}$ & 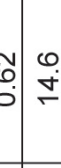 & $\frac{\rho}{\rho}$ & & 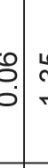 & & $\nabla$ & $\begin{array}{l}n^{2} \\
\end{array}$ & & \\
\hline 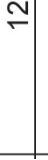 & 3 & $\begin{array}{c}\stackrel{9}{0} \\
\dot{\phi}\end{array}$ & 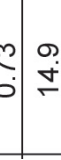 & | & . & 5 & & $\left.\right|^{\sigma}$ & 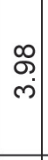 & 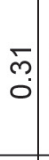 & $\begin{array}{l}\infty \\
0 \\
0 \\
0\end{array}$ \\
\hline
\end{tabular}




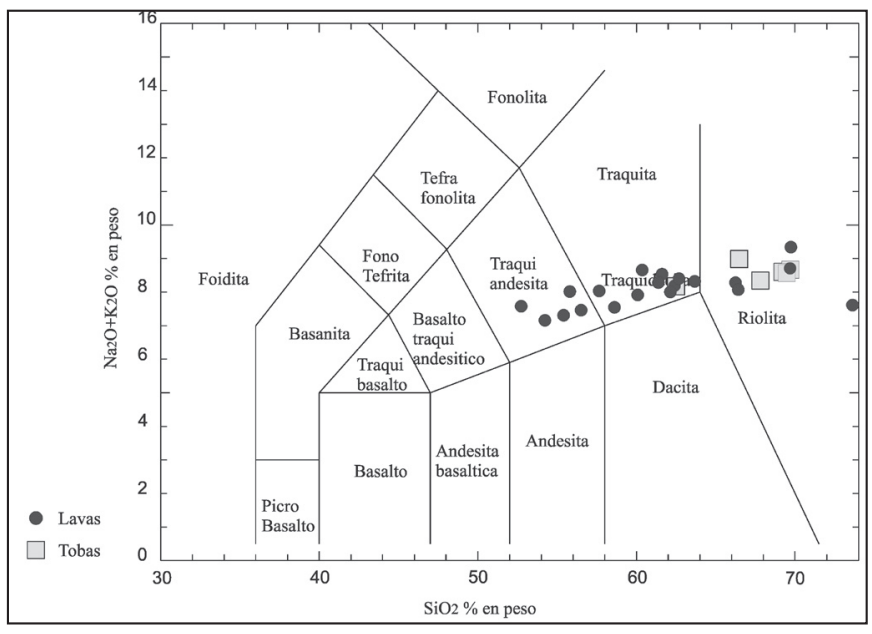

Figura 4. Diagrama de $\mathrm{SiO}_{2}$ vs álcalis (TAS), según Le Maitre et al. (1989) mostrando la distribución de las rocas del volcán Chullcani.

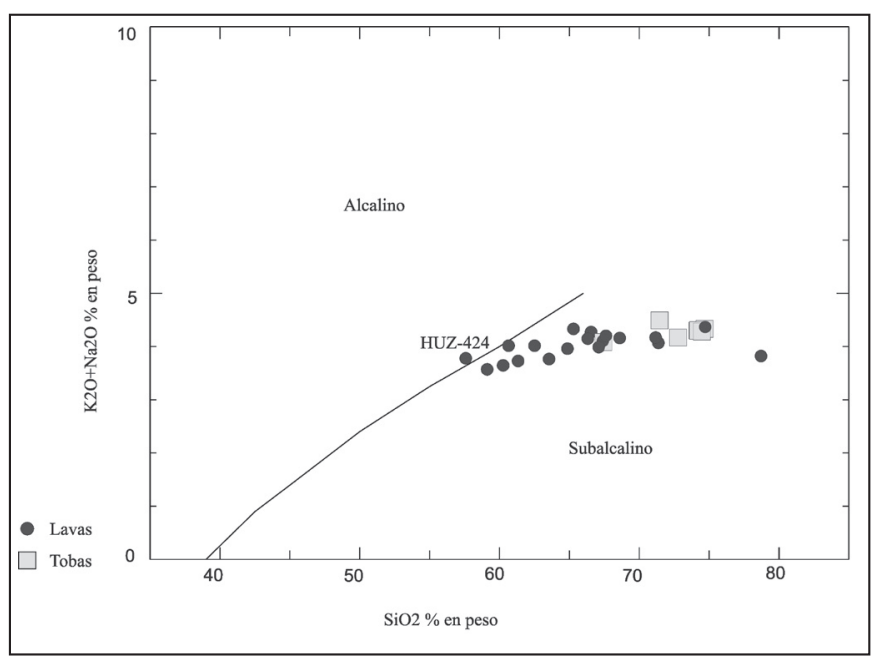

Figura 5. Diagrama sílice vs. Álcalis, según Harker (1909) mostrando como se distribuyen las rocas del Volcán Chullcani.

CONCLUSIONES Del análisis del presente estudio se concluye que; de acuerdo a la clasificación de nomenclatura y confirmados por el diagrama de $\mathrm{SiO}_{2}$ vs. álcalis las rocas del volcán Chullcani se encuentran dentro del campo de las rocas ácidas a intermedias.

Las muestras que caen en el campo de las traquidacitas, corresponden a los domos Jitiri y León Iquiña, las coladas de lava que caen en el campo de las traquiandesitas son del estratovolcán Chullcani, unidad Wuichukollu y unidad Carbon Kollu, el resto de las muestras caen en el campo de las riolitas que corresponden a las tobas y al domo Yapukkollu.

Los diagramas de discriminación de las series magmáticas nos permite determinar que las rocas involucradas en el área de estudio tienen carácter subalcalino y pertenecen a la serie calcoalcalina rica en potasio.

La evolución del Volcán Chullcani se desarrolló en dos periodos de tiempo, a inicios del Mioceno Medio y prosiguió en Plioceno Superior (Figura 8).

El primer periodo se caracterizó con la extrusión de los domos Changa Mokko y Yapukkollu (8a), para luego ser sobrepuestos por las tobas Khalani (8b), generadas por explosiones

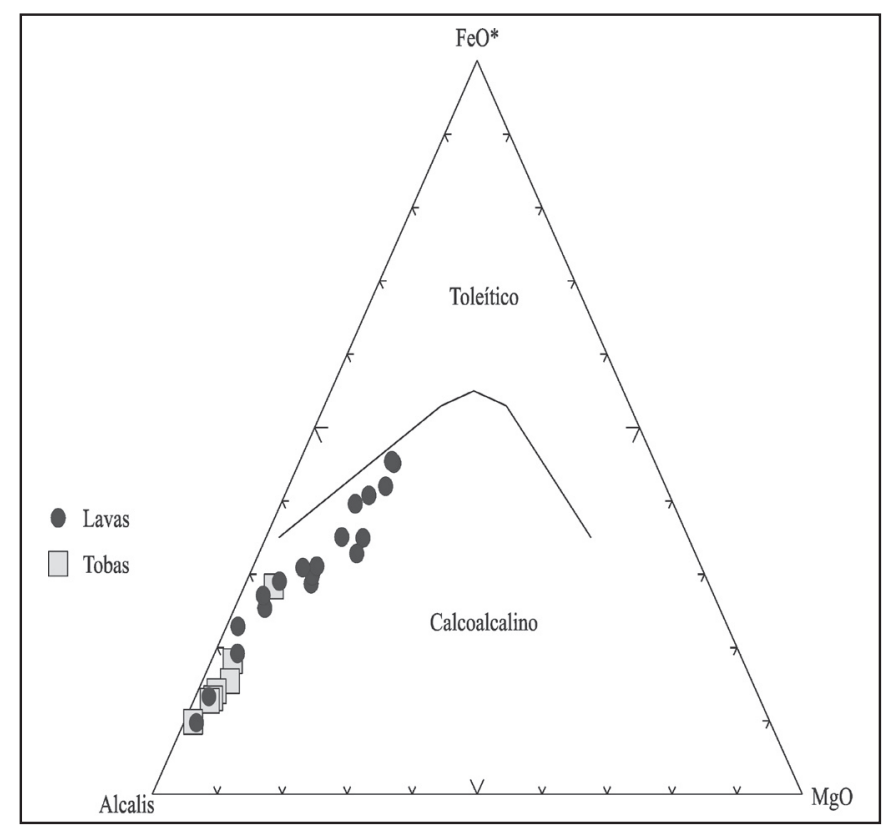

Figura 6. Diagrama AFM, modificado por Irvine \& Baragar en 1971, mostrando la tendencia calcoalcalina de las rocas del Volcán Chullcani

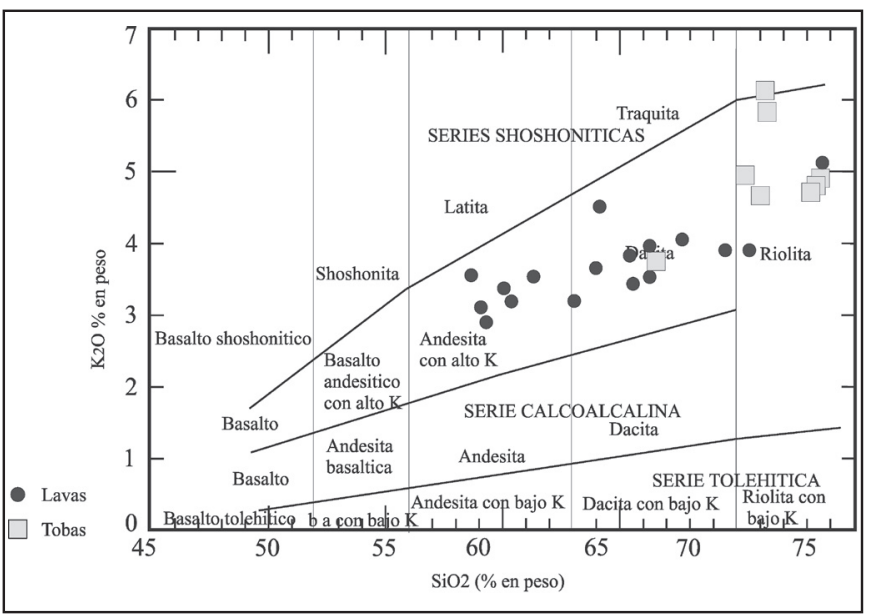

Figura 7. Diagrama de $\mathrm{SiO}_{2}$ vs. $\mathrm{K}_{2} \mathrm{O}$, Pecerrillo \& Taylor (1976), muestran que las rocas calcoalcalinas presentan un alto contenido de potasio.

del conducto central.

A partir de los $6.13 \pm 0.12 \mathrm{Ma}$ se depositaron las lavas andesíticas descritas como Estratovolcán Chullcani finalizando con la formación de los domos Jitiri y León Iquiña a los $6.2 \pm$ $0.4 \mathrm{Ma}(8 \mathrm{c})$.

El segundo periodo de actividad volcánica, (Plioceno Superior) se distinguió por la depositación de mantos ignimbriticos de la Formación Pérez a nivel regional en la zona volcánica central (8d), interrumpiendo parcialmente la evolución del Volcán Chullcani. Pero es a partir de los $2.3 \pm 0.2$ Ma que se reanudó la actividad con la extrusión de las lavas Wuichukollu para alternar con las tobas Ventilla, juntamente con las brechas volcánicas (8e). Finalizó esta intensa actividad con la formación de la meseta Carbon Kollu y el domo Pucara que actuó como un tapón sellando la actividad en la zona (8e). 
Reconstrucción geológica del volcán Chullcani (Mioceno Superior a Plioceno Superior): consideraciones generales sobre geoquímica y edad de las fases volcánicas, Andes Centrales de Bolivia.

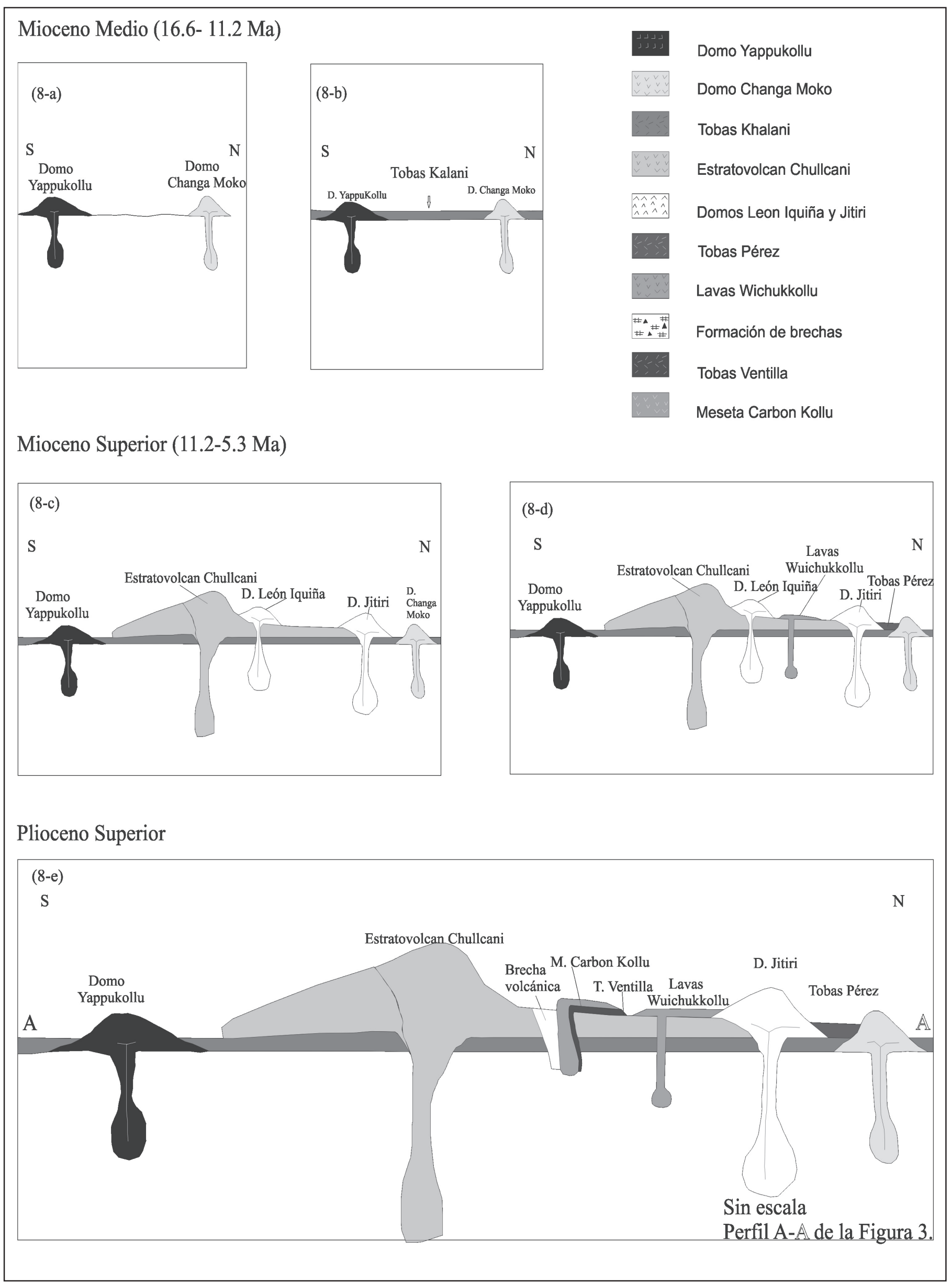

Figura 8. Evolución geológica del Volcán Chullcani 
Agradecimientos Se agradece a SERGEOTECMIN por permitir esta investigación, como parte de la tesis de licenciatura de la autora. Este estudio se realizó en el marco del Proyecto Multinacional Andino (PMA), que viene ejecutando desde 1996 trabajos de investigación geológica en Chile, Perú y Bolivia a través del Servicio Geológico Técnico Minero (SERGEOTECMIN) Bolivia juntamente con el Servicio Geológico de Canadá (SGC) y bajo el financiamiento del "Canadian Internacional De- velopment Agency (CIDA).

Los autores también agradecen a los revisores de la Revista Brasilera de Geociencias (RBG), cuyas observaciones y correcciones contribuyeron para la publicación de este trabajo, así como también al Ingeniero Néstor Jiménez, profesor de la Universidad Mayor de San Andres de La Paz-Bolivia por sus sugerencias oportunas.

\section{Referências}

Avila-Salinas W. 1971. Geología del Cuadrángulo Sajama, departamento de Oruro. La Paz, Sociedad de Ingenieros de Bolivia, v.15, 30 p.

Avila-Salinas W. 1994.Tectónica y Petrología del Macizo de Carangas (Andes Occidentales de Bolivia). In: Congreso Geológico de Bolivia,11, Santa Cruz, Memorias, p. 1-15.

Clavero J.E., Sparks R.S.J., Hoppert H.E., Dade W.B. 2002. Geological constraints on the emplacemente mechanism of the Parinacota debris avalanche, northern Chile. Bull. of volcanology, 64:40-54.

Forbes D. 1861. Report on the geology of South America. Part I. Bolivia and southern Peru, with notes on the fossils by Huxley, Salter and Jones. Quarterly Journal of the Geological Society of London, 17:7-62.

Harker A., 1909. The natural history of igneous rocks. Methuen, London.

Irvine T.N \& Barajar W.R.A., 1971. A guide to the chemical classification of the common volcanic rocks. Can. Journal Earth Sci., 8:523-548.

Jimenes N. \& Soler P. 1996. Series Magmáticas Cenozoicas de la Región Andina y su significado Geodinámico. In: Congreso Geológico de Bolivia, 12, Tarija, Memorias, p. 665-667.

Jimenes N., Galvan L., Palomino L. 2000. Geología de la región volcánica de Carangas: una revisión a partir de nuevos datos de campo. In: Congreso Geológico Boliviano,14, La Paz-Bolivia, Memorias, p. $284-288$

Le Maitre, R.W., Bateman, P., Dudek, A., Keller, J., Lameyre Le Bas, M.J., Sabine, P.A., Schmid, R., Sorensen, H., Streckeisen A., Woolwy A. R. Zanettin B., 1989. A classification of igneous rocks and glossary of terms. Blackwell, Oxford.

Ponce J., Avila-Salina W. 1964. Hoja Geológica de Sajama Hoja No. 6048, escala 1: 100 000. Servicio Geológico de Bolivia (GEO$\mathrm{BOL})$.
Pecerrillo R. \& Taylor S.R., 1976. Geochemestry of Eocenne calçalkaline volcanic rocks from the Kastamonu área, northern Turkey. Contrib. Mineral Petrol., 58:63-81

Rollinson H. 1995. Using Geochimical data: evolution, presentation, Interpretation. Longan Group Limited, Singapour, 352p.

Rösling R. 2000. Tectónica de placas y evolución estructural en el margen continental activo de Sudamérica, Revista Técnica de YPFB, vol. 18, N 1-2, 199-213.

Suarez Soruco R., Dias-Martinez. E. 1996. Léxico Estratigrafico de Bolívia. Revista Técnica de YPFB, vol. 17, N 1-2, 227 p.

Suarez Soruco R., Dias-Martinez. E. 2000. Compendio de Geología de Bolivia. Revista Técnica de YPFB, vol. 18, N 1-2, 213 p.

Sirvas-Carranza F. 1964. Estudio geológico de la región de Tambo Mauri- Berenguela, Prov. Pacajes. Tesis de Grado, UMSA (\# 35), La Paz, $81 \mathrm{p}$.

Tröeng B., Riera-Killibarda C., Mobarec-Clavijo R., Murillo-Salazar F. 1996. Mapa Temático de Recursos Minerales de Bolivia, Hoja Corque y Nevados Payachata. La Paz, SERGEOMIN vol. 11, 133 p.

Uribe-Zeballos H. 2000. Emplazamiento y Ocurrencias de Perlitas Asociadas a Flujos Riolíticos de Obsidiana, Altiplano Norte. In: Congreso Geológico Boliviano,14, La Paz-Bolivia, Atas. p 276-279.

Wörner G., Harmon R.S., Davidson J., Moorbath, S., Turner, D.L., Mcmillan, N., Nye, C., Lopez-Escobar \& Moreno H. 1988. The Nevados Payachata volcanic region $\left(18^{\circ} \mathrm{S} 69^{\circ} \mathrm{W}, \mathrm{N}\right.$. Chile): geological, geochimical and isotopic observation. Bulletin of vulcanology, 287303 .

Manuscrito A1627

Aprovado em 25 de outubro de 2006 